\title{
PHOSPHORYLATED CARBOHYDRATE INTERMEDIATES OF THE HUMAN ERYTHROCYTE DURING STORAGE IN ACID CIT- RATE DEXTROSE. II. EFFECT OF THE ADDITION OF INOSINE LATE IN STORAGE*
}

\author{
By GRANT R. BARTLETT AND A. WILLIAM SHAFER
}

(From The Scripps Clinic and Research Foundation, La Jolla, Calif.)

(Submitted for publication January 9, 1961 ; accepted March 16, 1961)

The preceding paper (1) describes the changes which were found in the glycolytic intermediates of the human erythrocyte during 8 weeks' storage of blood at $4^{\circ} \mathrm{C}$ in acid citrate dextrose (ACD) supplemented with the nucleoside, inosine.

Previous investigations had demonstrated that nucleosides not only were able to maintain a higher level of erythrocyte organic phosphate during storage but also that they could bring about a considerable resynthesis of organic from inorganic phosphate if added to the blood after several days of storage and then incubated for a few minutes at $37^{\circ} \mathrm{C}(2-4)$.

It was of interest, therefore, to extend our findings to a more detailed study of the nature of the phosphate compounds formed in the erythrocyte when nucleoside was added late in storage and to compare the results with those just described where inosine was present from the outset. In the experiments to be reported inosine was added to aliquots of human blood stored at $4^{\circ} \mathrm{C}$ in $\mathrm{ACD}$ : 1) after 3 weeks followed by another week at $4^{\circ} \mathrm{C}$, and 2) after 4 weeks followed by 1 or 3 hours of incubation at $37^{\circ} \mathrm{C}$. The phosphate compounds of the erythrocytes are compared with control samples kept for 4 weeks in ACD alone. It was considered worthwhile at this time to bring together available information on the metabolism of the stored red cell and to offer a tentative scheme to explain the events leading to loss of viability.

\section{METHODS}

Blood from a normal donor was drawn by gravity into ACD (NIH formula B) and stored at $4^{\circ}$ C. After 21 days of storage, $100 \mathrm{ml}$ of the ACD blood mixture was removed aseptically and to this was added inosine $(4 \mathrm{mg}$ per $\mathrm{ml}$ of blood) which had been autoclaved in normal saline in a concentration of $40 \mathrm{mg}$ per $\mathrm{ml}$. This sample

* Supported by the US Army Medical Research and Development Command, Office of the Surgeon General, and by the National Heart Institute. of blood was stored at $4^{\circ} \mathrm{C}$ for another 7 days. After 28 days of storage the remaining ACD blood was divided into three portions; one served as a control and to the other two the inosine solution was added to give a concentration of $4 \mathrm{mg}$ ( $15 \mu$ moles) per $\mathrm{ml}$ of original blood. The aliquots treated with inosine were incubated for 1 and 3 hours at $37^{\circ}$ C. Trichloroacetic acid extracts of the four samples were prepared, the metabolic intermediates were separated on columns of ion-exchange resin, and the compounds were analyzed as described in the preceding paper (1).

\section{RESULTS}

The phosphate compounds of the stored red cells were first isolated by column chromatography on Dowex-1 resin by chloride eluants, as shown in Figure 1. The $0.02 \mathrm{~N} \mathrm{HCl}$ elution section was rechromatographed by elution with ammonium formate buffer in order to separate the inosinic acid and adenosine diphosphate (ADP; Figure 2). Formate rechromatography was also carried out on the combined 0.003 and $0.01 \mathrm{~N} \mathrm{HCl}$ elution sections to obtain better resolution of the sugar monophosphates (Figure 3 ). The results are summarized in Figure 4, which for comparison includes data from the zero-day control and 4-week inosine experiments from the previous study (1).

We would like to focus attention first on adenosine triphosphate (ATP) whose concentration may prove to be the most critical factor in the survival of the cell. Several points are of interest. When inosine was present from the outset of storage there was little increase of ATP over that found in ACD alone, whereas much higher levels were found when the nucleoside was added later. The stored cells which were exposed to inosine during the fourth week at $4^{\circ} \mathrm{C}$ had an ATP concentration as high as in the initial blood, and it was only slightly lower in the 3 -hour $37^{\circ} \mathrm{C}$ incubation. It should be emphasized that a resynthesis of the ATP molecule took place, as will 


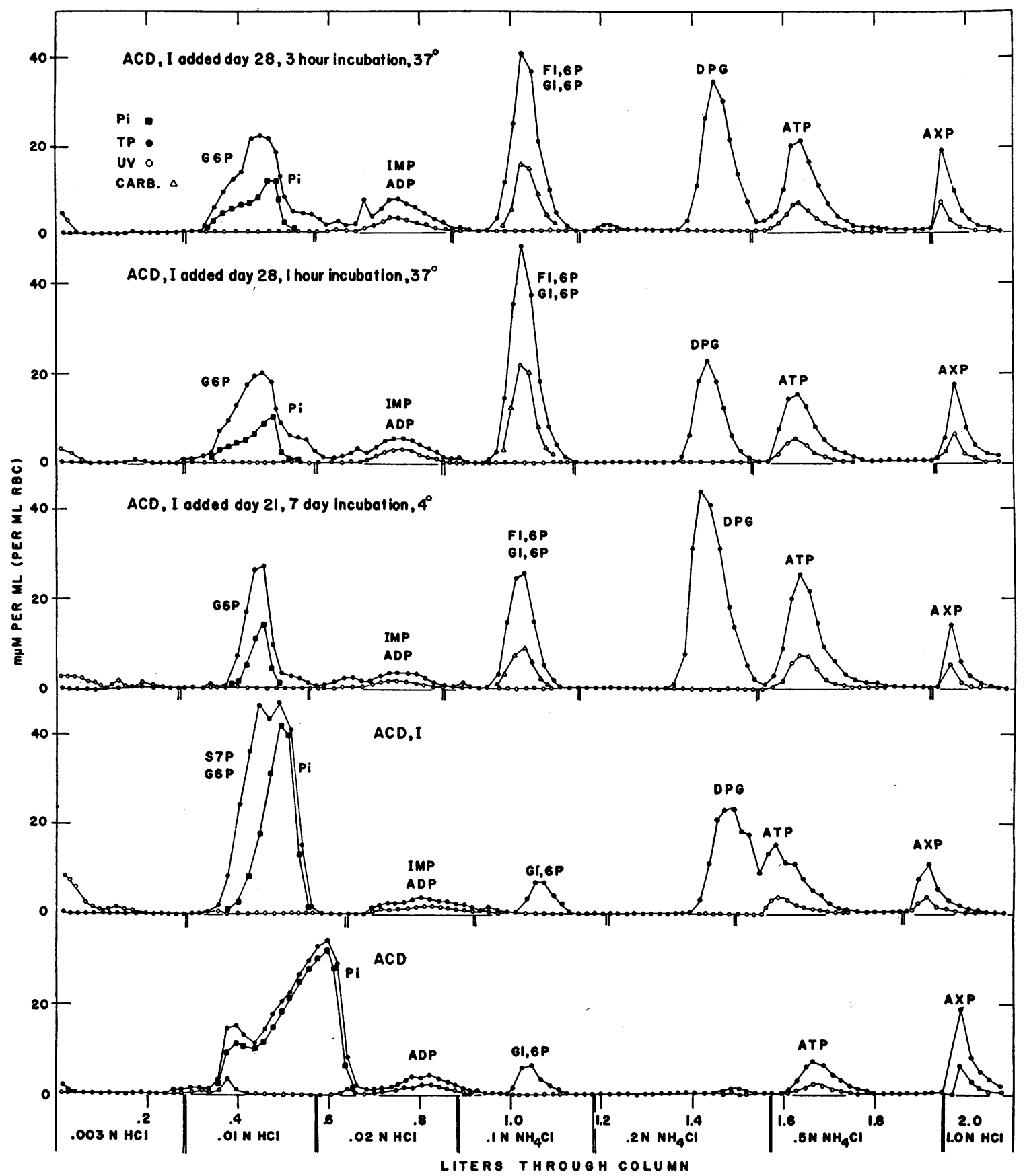

Fig. 1. ION-EXChange Chromatographs OF TRICHLOROACETIC ACID EXTRACTS OF HUMAN ERYTHROCYTES STORED FOR 28 DAYS IN ACD ALONE OR WITH INOSINE ADDED (ACDI) AT THE BEgINNING OR LATE IN STORAGE, AS INDICATED. The data are plotted in $\mathrm{m} \mu$ moles per $\mathrm{ml}$ of eluate (calculated for $1 \mathrm{ml}$ of red cells). Total phosphorus (TP), $\bullet$; adenine (from the optical density at $260 \mathrm{~m} \mu$ ), $\mathrm{O}$; inorganic phosphate $(\mathrm{Pi}), \mathbf{\square}$; carbazole assay for fructose (carb.), $\triangle$. Abbreviations: G6P, glucose-6-phosphate, S7P, sedoheptulose-7-phosphate; ADP, adenosine diphosphate; IMP, inosine monophosphate; G1,6P, glucose-1,6-diphosphate; F1,6P, fructose-1,6-diphosphate; DPG, 2,3diphosphoglycerate; ATP, adenosine triphosphate; AXP, unknown nucleotide. 


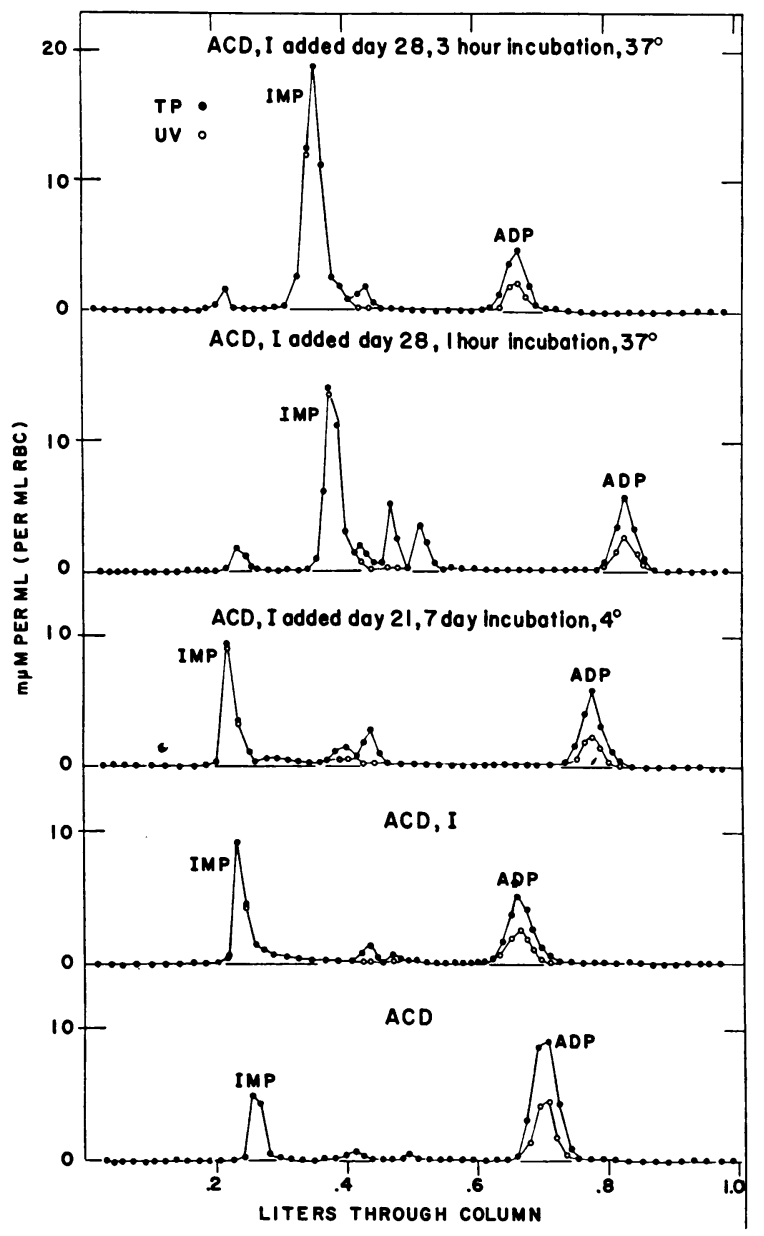

Fig. 2. Rechromatograph of the $0.02 \mathrm{~N}$ HCl SeCTIONS OF THE DoWEX CHLORIDE CHROMATOGRAPHS SHOWN IN Figure 1. The pooled eluates were passed through $1 \times 15 \mathrm{~cm}$ columns of Dowex $1 \times 8$ formate (100 to 325 wet mesh) which were eluted at $1 \mathrm{ml}$ per minute with $1 \mathrm{~L}$ of linear gradient zero to $1 \mathrm{~N}$ ammonium formate. See Figure 1 for abbreviations.

be discussed in more detail below. For example, the 3-hour incubation at $37^{\circ} \mathrm{C}$ produced a concentration of ATP more than double that of the 4-week control. Since no other precursors appear to be available, it seems most probable that the hypoxanthine part of the inosine gave rise to the adenine ring of ATP.

The changes in the concentration of ATP under the different conditions of storage were not reflected in any striking alteration of ADP. There was some increase in this intermediate in the red cells stored with inosine during the fourth week and a decrease in those incubated at $37^{\circ} \mathrm{C}$. Inosinic acid, however, increased considerably during the $37^{\circ} \mathrm{C}$ incubations. Since this was clearly a condition of net synthesis of total adenylate, the inosinate must have originated from inosine rather than from adenylate and so was probably an intermediate in the synthesis of ATP from the nucleoside. No significant amounts of adenosine monophosphate (AMP) built up under any of the experimental conditions.

One of the most interesting chemical characteristics of the red cells which were stored from the beginning with inosine was that they accumulated relatively large quantities of glucose-6-phosphate and sedoheptulose-7-phosphate. In contrast, when the incubation was performed at $37^{\circ} \mathrm{C}$, much smaller levels of the sugar monophosphates were present but a very large amount of fructose diphosphate appeared. A block in the metabolic path from ribose phosphate at the triose phosphate oxidation step might be expected to cause a piling up of fructose diphosphate.

Pentose phosphates did not appear in appreciable amounts in any of the experiments and presumably were metabolized as rapidly as formed from inosine. Glucose diphosphate showed a moderate increase above the zero time value in all of the incubations with inosine.

As demonstrated in previous studies, diphosphoglycerate (DPG) disappears almost completely after 4 weeks of storage in ACD. The incubations with inosine, either during the fourth week at $4^{\circ}$ $\mathrm{C}$ or for 3 hours at $37^{\circ} \mathrm{C}$ at the end of 4 weeks, although restoring ATP to essentially zero time levels, reformed only 30 to 40 per cent of the original concentration of DPG. Even so, this represents a considerable synthesis and indicates that the initial drop in $\mathrm{pH}$ produced by the $\mathrm{ACD}$ preservative cannot be the major factor responsible for the rapid early loss of DPG, since the metabolism of inosine tends to lower the $\mathrm{pH}$ even further during storage. The variations of DPG were not accompanied by any notable changes in the concentration of monophosphoglycerate which was present in only very small amounts.

Although the inorganic phosphate inside of the red cell rose reciprocally as the organic phosphate fell during storage in ACD, an appreciable amount leaked out into the plasma so that the total phosphorus at 4 weeks was only 60 per cent of that at zero time. The various incubations with inosine, especially late in storage, not only utilized 


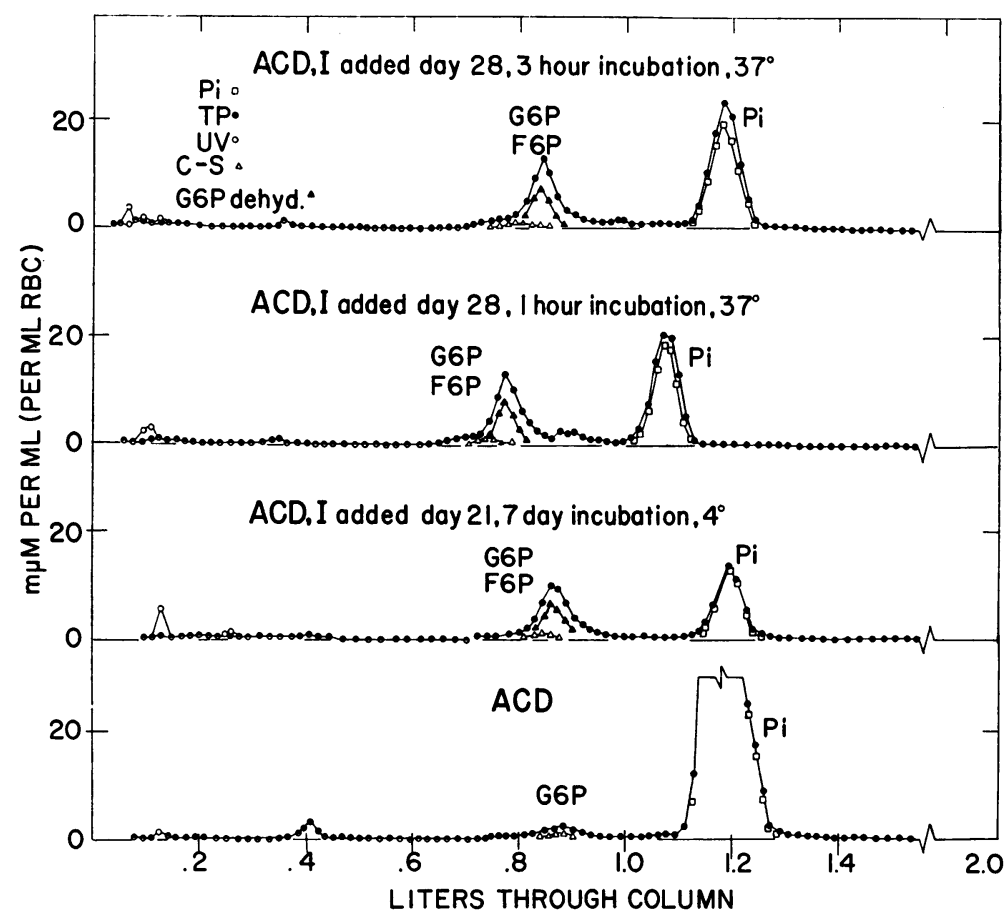

Fig. 3. Rechromatograph of the $0.01 \mathrm{~N}$ HCl sections of the chloRIDE CHROMATOGRAPHS SHOWN IN FIGURE 1 . The pooled eluates were passed through $1 \times 15 \mathrm{~cm}$ columns of Dowex $1 \times 8$ formate (100 to 325 wet mesh) which were eluted at $1 \mathrm{ml}$ per minute with $2 \mathrm{~L}$ of linear gradient zero to $1 \mathrm{~N}$ formic acid. The data are plotted in $\mathrm{m} \mu$ moles per $\mathrm{ml}$ of eluate (calculated for $1 \mathrm{ml}$ of erythrocytes). See Figure 1 for abbreviations. Cysteinesulfuric acid assay for sedoheptulose (C-S), $\triangle$; glucose-6-phosphate dehydrogenase assay for glucose-6-phosphate (G6P dehyd.),

intracellular inorganic phosphate for synthesis but also used some of the extracellular phosphate, bringing the total phosphorus of the cell back to approximately 80 per cent of the original.

\section{DISCUSSION}

Studies from this laboratory and elsewhere on the metabolism of stored blood are consistent with the view that an intact functioning glycolytic apparatus is indispensable to the erythrocyte if it is to survive preservation at above-freezing temperatures. The glycolytic capacity declines during storage, as demonstrated by the inability of glucose to maintain the normal concentration of intermediate metabolites within the cell. It is of theoretical importance for future research, although apparently of little practical value at this time, that inosine can to a certain extent replace glucose; it can restore some of the metabolites and under limited conditions prolong the survival of the erythrocyte. The metabolic effects of inosine can be explained by the fact that it penetrates easily into the erythrocyte and is split by nucleoside phosphorylase to give ribose phosphate and hypoxanthine. The ribose phosphate is changed to other pentose phosphates which are rearranged by the enzymes transketolase and transaldolase to produce fructose phosphate and triose phosphate and so enter the glycolytic pathway. These reactions-a portion of the so-called pentose shunt-are commonly found in many kinds of tissues (5).

The changes in the concentrations of ATP and DPG which were found in the erythrocyte under the various storage conditions reported here are of special interest and illustrate some of the complexities involved in trying to diagnose the state of the metabolic machinery. The experiments show a rapid loss of 2,3-diphosphoglycerate from the erythrocytes stored in ACD and extensive resynthesis during the incubation with inosine. The 


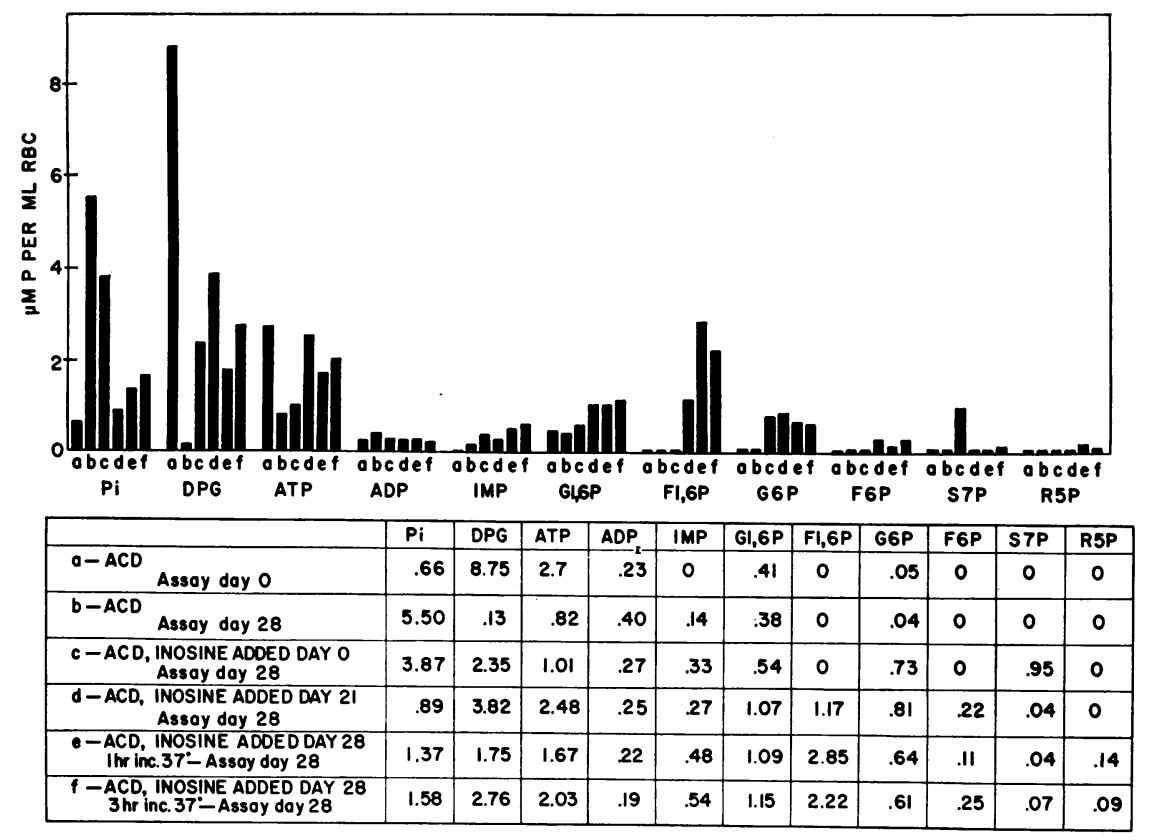

Fig. 4. Summary of Changes of phosphate compounds of human erythroCytes Stored in ACD with addition of inosine at Different times. The figures in the table are expressed in $\mu$ moles of phosphorus per $\mathrm{ml}$ of erythrocytes. Samples $\mathrm{b}, \mathrm{d}$, e, and $\mathrm{f}$ were blood drawn at the same time from one donor. Data listed under a and $\mathrm{c}$ are duplications of results reported in the previous paper; blood from a different donor.

enzyme, monophosphoglycericmutase, which carries out the interconversion of 2-monophosphoglycerate and 3-monophosphoglycerate with 2,3diphosphoglycerate as a cofactor, is unable to bring about any synthesis or breakdown of the 2,3-diphosphoglycerate. Rapoport and Luebering (6-8) discovered two enzymes in the human erythrocyte which could account for net changes in the concentration of 2,3-diphosphoglycerate. These are: 1) diphosphoglycerate mutase which can convert 1,3-diphosphoglycerate to 2,3-diphosphoglycerate, and 2) a specific phosphatase which splits one of the phosphates from 2,3-diphosphoglycerate to give 2-monophosphoglycerate. Rapoport, Luebering and Nieradt (6-9) suggested that a cycle passing from 1,3-diphosphoglycerate to 2,3-diphosphoglycerate to 2-monophosphoglycerate may represent the main route of glycolysis in the erythrocyte [see Altman (10) for discussion of this concept]. However, during the steady state of normal metabolism in the human erythrocyte, significant participation of this cycle can be ruled out from the $\mathrm{P}^{32}$-labeling data which are consistent with a process that transfers most of the phosphorus from the carboxyl group of 1,3-diphosphoglycerate to ADP, to give 3-monophosphoglycerate which is then converted through the phosphoglycericmutase reaction to 2-monophosphoglycerate and so on (11). Although the cycle does not appear to be operating under normal conditions, it can explain some of the changes observed during storage. Grisolia (12) has confirmed and extended these findings of Rapoport and co-workers, showing that 3-monophosphoglycerate accelerates the conversion of 1,3-diphosphoglycerate to 2,3-diphosphoglycerate and inhibits the 2,3-diphosphoglycerate phosphatase. With this background the events taking place during storage can be reconstructed as follows. When 1,3-diphosphoglycerate and 3-monophosphoglycerate are no longer being produced because of a defect higher in the metabolic path, the 3-monophosphoglycerate inhibition of the phosphatase is released, and the 2,3-diphosphoglycerate disappears rapidly by hydrolysis to monophosphoglycerate which can be converted to lactate. When 1,3-diphosphoglycerate and 3-monophosphoglycerate are replenished from the catabolism of ino- 
sine, the 3-monophosphoglycerate blocks the phosphatase split of 2,3-diphosphoglycerate and stimulates its formation from 1,3-diphosphoglycerate. The 3-monophosphoglycerate kinase and the diphosphoglycerate mutase continue as competing reactions until the level of the 2,3-diphosphoglycerate is raised high enough to inhibit its further synthesis, at which time the kinase takes over as the primary reaction for the conversion of 1,3diphosphoglycerate to 3-monophosphoglycerate.

Not only ATP but total adenine nucleotide was reduced in the erythrocyte during storage in ACD and could be regenerated in the presence of inosine. It seems of special importance to try to understand the mechanisms involved. The socalled de novo synthesis of purine nucleotide from small units such as glycine and formate has been intensively investigated in recent years, and a rather complex path has emerged which seems to be widely distributed in nature (13). Human or rabbit erythrocytes lack the capacity to carry out this over-all de novo synthesis of purine nucleotide (14). However, another important pathway for the biosynthesis of purine nucleotide is by the reaction of preformed purine with phosphoribosylpyrophosphate to give the nucleoside, $5^{\prime}$ phosphate (15). It has been demonstrated that the intact human or rabbit erythrocyte can incorporate $\mathrm{C}^{14}$ labeled adenine or hypoxanthine into adenylate $(16,17)$ presumably by a reaction with phosphoribosylpyrophosphate. Moreover, extracts of human erythrocytes have been found to make phosphoribosylpyrophosphate and to react it with adenine or hypoxanthine to give nucleotide (18). From these observations it seems probable that the first step in the net synthesis of adenylate from inosine seen in the stored cells is the reaction of hypoxanthine (from inosine) with phosphoribosylpyrophosphate to give inosinic acid. Apparently the major route for the conversion of inosinate to adenylate in most kinds of cells is by a reaction with aspartate to give adenylosuccinate which splits to adenylate (19). This reaction has not been examined in the erythrocyte. One other possibility for the synthesis of nucleotide by the erythrocyte must be kept in mind and that is a direct phosphorylation of nucleoside, although this reaction is not generally thought to comprise an important fraction of purine nucleotide formation in the animal (20).
Instead of speaking of ATP alone, it is more instructive to consider the combined AMP-ADPATP pool and divide it into two parts: 1) the fraction in the form of high energy phosphate, and 2) the content of total adenylate. In the normal cell the fraction as ATP is very high, and the amount of high energy phosphate entering the pool from the reactions of the glycolytic chain is balanced by the amount going out through phosphorylations of hexose and hexose phosphate and the action of ATPases. The total adenylate is kept constant with a small but significant turnover of the AMP-unit during the life of the cell, as shown by Lowy, Ramot and London (16). During storage in ACD both the high energy phosphate and the total adenylate decrease. As will be discussed later, we believe that a defect early in the glycolytic path decreases the amount of high energy phosphate coming into the adenylate pool. If we assume that the usual ATPase activities continue, then the ATP concentration will fall. Due to the presence of a potent adenylate kinase (21-23), the ADP formed by the action of ATPase will be converted to AMP and ATP, and this process will continue until all of the adenylate is changed into AMP. However, we did not find AMP accumulating in the stored cells and must postulate that some mechanism is released which increases the rate of its breakdown above the normal. This could be a direct effect of increased concentration of AMP on the enzyme involved, or it might result from the disappearance of an inhibitor (for example, ATP). The first step in the degradation of the AMP is probably mediated by the enzyme 5 -nucleotidase (24) either before or after deamination (25) to inosinate, or perhaps both. We have seen that a small amount of inosinic acid accumulates during the storage. The products of the $5^{\prime}$-nucleotidase, adenosine (after conversion to inosine by a nucleoside deaminase) $(26,27)$ and inosine, would be split to hypoxanthine and ribose phosphate by nucleoside phosphorylase (28-30). Several studies have shown that hypoxanthine is the principal endproduct of nucleotide decomposition in the erythrocyte (31-33). The hypoxanthine and a small fraction of xanthine are not further changed to uric acid due to the absence of xanthine oxidase.

Although addition of inosine after 4 weeks of storage brought about a considerable resynthesis of 
ATP, there is some evidence for the belief that adenosine may be more effective than inosine in reversing the metabolic defect of the stored red cell, as re-emphasized recently by Mollison and Robinson (34). Most of the early favorable experiments of Gabrio, Donohue and colleagues were performed with adenosine (2-4). Further light on the matter has come from the studies of Nakao, Nakao, Tatibana and Yoshikawa (35) who have reported that, after several weeks of storage when inosine shows a decreasing effectiveness for the formation of ATP, inosine plus adenine gives better results. Any increased effect of adenosine is presumably through the formation of adenine, since the reaction of phosphoribosylpyrophosphate with hypoxanthine or adenine, from present information, would be the preferred route of nucleotide synthesis. Experiments in progress in our laboratories (36) confirm these impressions. The results show, for example, that after 10 weeks of cold storage in ACD, adenosine, or adenine plus inosine, is much more effective than inosine alone in increasing the level of ATP in the human erythrocyte. The lesser efficiency of inosine could be due to a deficiency in the ability of the cell to convert inosinic acid to adenylic acid.

We feel at this time that the most likely site of the primary defect in the metabolism of the stored erythrocyte is the first step in the utilization of glucose. This step is a complex of several components including traversal of the outer membrane by the sugar, probable selective orientation of the hexokinase protein within a double membrane cell coat, concentration of magnesium ion, and undoubtedly other unknown coenzymatic determinants of the enzyme activity and the supply of ATP. An initial loss of ATP from whatever cause could of course block glucose utilization. However, it is unlikely that this is the primary reason for the storage defect in view of the fact that the fall in concentration of diphosphoglycerate precedes that of ATP. As the rate of consumption of glucose decreases in the stored erythrocytes, the levels of the glycolytic intermediates fall as if they were continuing to move through the metabolic channel from glucose-6-phosphate to lactate without being replenished. On their way to lactate these phosphate intermediates help maintain the level of ATP which decreases more slowly. When inosine is added to this defective cell, the metabolism of ribose feeds into the glycolytic path at the fructose-6-phosphate and triose phosphate steps and produces significant quantities of glucose-6-phosphate, fructose diphosphate, diphosphoglycerate, and lactate, at the same time renewing the ATP. This proves that the individual reaction steps of glycolysis are still intact late in storage from glucose-6-phosphate on.

We know that there is a critical period during storage when the red cell which would have been removed rapidly from the circulation upon transfusion will survive if it has had a treatment with nucleoside. It is unlikely that nucleosides are present in the blood stream in amounts sufficient to continue to serve as the principal substrate for the erythrocyte, and it seems most probable that somehow the ability to use glucose is restored in the body. Assuming such a reversibility of the storage lesion to be the case, and that the phosphorylation of glucose is involved, what are possible contributing factors? Protein denaturation can be ruled out, since as far as is known the mature erythrocyte cannot synthesize protein and so would not be able to make any new hexokinase enzyme after returning to the circulation. As mentioned, the hexokinase reaction is probably located in the surface area of the cell and so is vulnerable to influences which would cause loss to the storage medium of controlling cofactors for the enzyme-agents which could reasonably be regained in the more favorable environment of the circulation. It is also conceivable that reactions selectively localized in the cell membrane have a restricted orientation vis a vis the exterior and interior, distortion of which by the highly abnormal medium might lead to decreased enzyme activity, an inhibition which could be eliminated on return of the erythrocyte to the circulation.

In summary, a tentative scheme has been formulated to explain the storage lesion (Figure 5) with the metabolic pathways severely abbreviated for the sake of simplicity (single arrows designate a reaction involving one phosphate; double arrows, two phosphates). During normal glycolysis the phosphate bond energy gained from the conversion of glucose to lactate is transferred to the adenylate pool at reactions 1 and 2, donating four high energy phosphate bonds per molecule of hexose metabolized. Two of these phosphates are used to phosphorylate hexose and hexose 


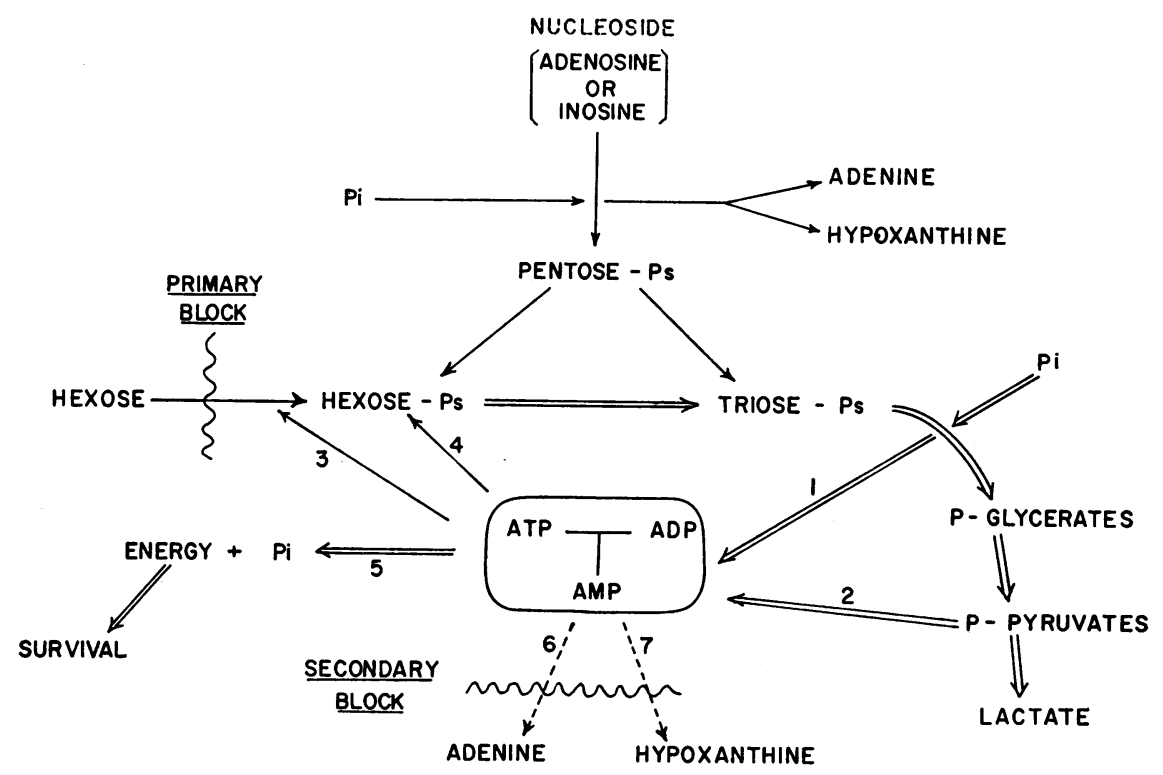

Fig. 5. Tentative SCheme for Red Cell Storage lesion.

monophosphate (reactions 3 and 4) and the other two (step 5) are used in reactions related to the preservation of cellular viability. The system is normally in balance so that the concentration of ATP remains constant. During storage, the initial defect at the first step of glucose utilization slows the flow of carbon through the glycolytic pipeline and so decreases the amount of phosphorus entering the adenylate pool. The outflow of phosphorus at reaction 5 is not affected or is perhaps even increased and so the ratio of ATP to AMP falls. A rising concentration of AMP accelerates the breakdown at reactions 6 and 7, displacing the normal small and equal rate of synthesis and degradation. The resulting drop in concentration of ATP further decreases the rate of phosphorylation of glucose and thus a vicious circle is established, accelerating the decay of the metabolic system. Inosine does two different and essential things to rebuild ATP levels. In the first place, it supplies the alternate substrate ribose phosphate which is able to enter the metabolic path beyond the storage lesion and generate high energy phosphate bonds. Secondly, the increased supply of hypoxanthine reverses reaction 7 to give new adenylate acceptor for the high energy phosphate. As discussed above, the route from adenine to adenylate may prove to be more efficient than that from hypoxanthine. A relatively high level of ATP in the erythrocyte at the time of transfusion is required to give it enough resilience to maintain its integrity through that period of circulation in the body before the primary storage defect is reversed and the erythrocyte resumes its normal metabolism of glucose.

\section{SUMMARY}

The effect of inosine on the phosphorylated metabolic intermediates of the human erythrocyte stored at $4^{\circ} \mathrm{C}$ in acid citrate dextrose preservative was determined after the addition of the nucleoside: 1) after 3 weeks followed by another week at $4^{\circ} \mathrm{C}$, and 2 ) after 4 weeks followed by 1 or 3 hours of incubation at $37^{\circ} \mathrm{C}$. Inosine produced extensive resynthesis of some of the organic phosphates normally present in the fresh erythryocyte and led to important quantitative and qualitative changes in the normal pattern of metabolites. In the light of the results found here and reported elsewhere a scheme has been proposed to explain the biochemical events leading to a loss in viability of the stored erythrocyte.

\section{REFERENCES}

1. Shafer, A. W., and Bartlett, G. R. Phosphorylated carbohydrate intermediates of the human erythrocyte during storage in acid citrate dextrose. I. Effect of the addition of inosine at the beginning of storage. J. clin. Invest. 1961, 40, 1178.

2. Gabrio, B. W., Donohue, D. M., and Finch, C. A. Erythrocyte preservation. V. Relationship be- 
tween chemical changes and viability of stored blood treated with adenosine. J. clin. Invest. 1955 34, 1509 .

3. Gabrio, B. W., Hennessey, M., Thomasson, J., and Finch, C. A. Erythrocyte preservation. IV. In vitro reversibility of the storage lesion. J. biol. Chem. 1955, 215, 357.

4. Donohue, D. M., Finch, C. A., and Gabrio, B. W. Erythrocyte preservation. VI. The storage of blood with purine nucleosides. J. clin. Invest. 1956, $35,562$.

5. Dickens, F. Recent advances in knowledge of the hexose monophosphate shunt. Ann. N. Y. Acad. Sci. 1958, 75, 71 .

6. Rapoport, S., and Luebering, J. The formation of 2,3-diphosphoglycerate in rabbit erythrocytes: The existence of a diphosphoglycerate mutase. J. biol. Chem. 1950, 183, 507.

7. Rapoport, S., and Luebering, J. An optical study of diphosphoglycerate mutase. J. biol. Chem. 1952, 196, 583.

8. Rapoport, S., and Luebering, J. Glycerate-2,3-diphosphatase. J. biol. Chem. 1951, 189, 683.

9. Rapoport, S., and Nieradt, C. Inwieweit verläuft die Glykolyse im Säugetiererythrocyten über 2,3-Diphosphoglycerinsäure? Über eine Variante des glycolytischen Cyclus auf dem Niveau der Phosphoglycerinsäuren. Biochem. Z. 1955, 326, 231.

10. Altman, K. I. Some enzymologic aspects of the human erythrocyte. Amer. J. Med. 1959, 27, 936.

11. Bartlett, G. R. Unpublished observations.

12. Grisolia, S. Energy-generating systems. Ann. N. Y. Acad. Sci. 1959, 72, 462.

13. Buchanan, J. M. Biosynthesis of purine neucleotides in The Nucleic Acids, E. Chargaff and J. N. Davidson, Eds. New York, Academic Press, 1960, vol. III, p. 303.

14. Lowy, B. A. Studies on purine nucleotide biosynthesis in the rabbit erythrocyte in The Kinetics of Cellular Proliferation, F. Stohlman, Ed. New York, Grune \& Stratton, 1959, p. 122.

15. Kornberg, A., Lieberman, I., and Simms, E. S. Enzymatic synthesis of purine nucleotides. J. biol Chem. 1955, 215, 417.

16. Lowy, B. A., Ramot, B., and London, I. M. The biosynthesis of adenosine triphosphate and guanosine triphosphate in the rabbit erythrocyte in vivo and in vitro. J. biol. Chem. 1960, 235, 2920.

17. Bishop, C. Purine metabolism in human and chicken blood, in vitro. J. biol. Chem. 1960, 235, 3228.

18. Preiss, J., and Handler, P. Enzymatic synthesis of nicotinamide mononucleotide. J. biol. Chem. 1957, 225,759

19. Lieberman, I. Enzymatic synthesis of adenosine-5'phosphate from inosine- $5^{\prime}$-phosphate. J. biol. Chem. 1956, 223, 327.

20. Kornberg, A. Pathways of enzymatic synthesis of nucleotides and polynucleotides in A Symposium on the Chemical Basis of Heredity, W. D. McElroy and B. Glass, Eds. Baltimore, Johns Hopkins Press, 1957, p. 579.
21. Kashket, S., and Denstedt, O. F. The metabolism of the erythrocyte. XV. Adenylate kinase of the erythrocyte. Canad. J. Biochem. 1958, 36, 1057.

22. Tatibana, M., Nakao, M., and Yoshikawa, H. Adenylate kinase in human erythrocytes. J. Biochem. (Tokyo) 1958, 45, 1037.

23. Gerlach, E., and Lübben, K. Der Phosphat-Stoffwechsel in Tauben- und Menschen-Erythrocyten unter dem Einfluss von 2,4-Dinitrophenol, Natriumcyanid, Monojodacetat sowie von Thyroxin and Triäthylenmelamin. Pflüg. Arch. ges. Physiol. 1959, 269, 520.

24. Heppel, L. A., and Hilmoe, R. J. Purification and properties of 5-nucleotidase. J. biol. Chem. 1951, 188, 665.

25. Lee, Y. P. 5'-Adenylic acid deaminase. I. Isolation of the crystalline enzyme from rabbit skeletal muscle. II. Homogeneity and physicochemical properties. III. Properties and kinetic studies. J. biol. Chem. 1957, 227, 987, 993, 999.

26. Rubinstein, D., Kashket, S., Denstedt, O. F., and Gosselin, S. M. Studies on the preservation of blood. IV. The influence of adenosine on the glycolytic activity of the erythrocyte during storage at $4^{\circ}$ C. Canad. J. Biochem. 1956, 34, 61.

27. Rubinstein, D., and Denstedt, O. F. The metabolism of the erythrocyte. XIV. Metabolism of nucleosides by the erythrocyte. Canad. J. Biochem. 1956, 34, 927.

28. Huennekens, F. M., Nurk, E., and Gabrio, B. W. Erythrocyte metabolism. I. Purine nucleoside phosphorylase. J. biol. Chem. 1956, 221, 971.

29. Sandberg, A. A., Lee, G. R., Cartwright, G. E., and Wintrobe, M. M. Purine nucleoside phosphorylase activity of blood. I. Erythrocytes. J. clin. Invest. 1955, 34, 1823.

30. Tsuboi, K. K., and Hudson, P. B. Enzymes of the human erythrocyte. I. Purine nucleoside phosphorylase; isolation procedure. J. biol. Chem. 1957, 224, 879.

31. Chen, P. S., Jr., and Jorgensen, S. Formation of hypoxanthine from adenosine triphosphate in shed human blood. Acta pharmacol. (Kbh.) 1956, 12, 369.

32. Jorgensen, S. Adenine nucleotides and oxypurines in stored donor blood. Acta pharmacol. (Kbh.) 1957, 13, 102.

33. McLellan, W. L., and Lionetti, F. J. Hypoxanthine production from nucleosides in erythroctye ghosts. J. biol. Chem. 1959, 234, 3243.

34. Mollison, P. L., and Robinson, M. A. Observations on the effects of purine nucleosides on red-cell preservation. Brit. J. Haemat. 1959, 5, 331.

35. Nakao, M., Nakao, T., Tatibana, M., and Yoshikawa, $\mathrm{H}$. Phosphorus metabolism in human erythrocyte III. Regeneration of adenosine triphosphate in long-stored erythrocyte by incubation with inosine and adenine. J. Biochem. (Tokyo) 1960, 47, 661.

36. Shafer, A. W., and Bartlett, G. R. Unpublished observations. 